\title{
Instructor Methods and Curricular Effects on Students' Value of Lectures
}

\author{
Garrett Schick $^{1}$ [D David McWhorter ${ }^{1}$
}

Accepted: 3 November 2021 / Published online: 2 December 2021

(c) The Author(s) under exclusive licence to International Association of Medical Science Educators 2021

\begin{abstract}
Background Lectures remain a common instructional method in medical education. Instructor methods, curricular factors, and technology affect students' use of scheduled live lectures that may impact faculty job satisfaction.

Aim This study identified instructor methods and curriculum issues that influenced preclinical medical students' use of scheduled lectures as well as faculty perceptions of lectures and students' attendance.

Methods First- and second-year osteopathic medical students $(n=304)$ were invited to complete a voluntary, anonymous semantic differential scale, Likert scale, and dichotomous question survey, rating 22 lecturer methods and 9 curriculum factors that influence use of live lectures. Preclinical faculty $(n=35)$ were also asked to complete a differential scale survey, rating 17 issues regarding live lectures and student attendance. Student and faculty surveys were analyzed using the appropriate central tendency and variability measures.

Results Students that completed the survey $(n=144)$ rated the ability to explain complex concepts in an understandable manner as "Very Important" and wearing professional attire as "Not Important" for attending lectures, respectively. Availability of recorded lectures, time to an upcoming exam, and unscheduled time gaps between lectures were rated as Very Important curricular factors for attending lectures. Faculty completed the survey $(n=21)$ and agree that lectures should continue as a major mode of instruction, while the majority reported spending over $9 \mathrm{~h}$ preparing new lectures.

Conclusions Faculty lecture methods and overarching curricular decisions greatly impact students' attendance of live lectures. Regardless, most students and faculty believe that scheduled lectures should continue as an option for students who prefer to attend live lectures.
\end{abstract}

Keywords Instructor methods · Lecture attendance $\cdot$ Curriculum factors $\cdot$ Faculty satisfaction $\cdot$ Lecture preparation · Medical education

\section{Introduction}

Regardless of instructional format (e.g., flipped classroom, problem-based learning, and team-based learning), lecture remains one of the most common teaching and learning methods in medical education [1,2]. In person lectures allow for a time-efficient delivery of contemporary information to a large group of students by a content expert [3], as well as the use of interactive activities in a lecture hall

Garrett Schick

gschick@arcomedu.org

David McWhorter

david.mcwhorter@arcomedu.org

1 Arkansas College of Osteopathic Medicine, 7000 Chad Colley Blvd, Fort Smith, AR, USA to promote active learning such as TurningPoint ${ }^{\circledR}$ [4]. Campbell and colleagues [5] reported that faculty believe attending live lecture was important for student social interactions. With advancements in technology, such as recorded lectures and numerous free content-rich educational resources, there has been a decline in lecture attendance $[6,7]$. Consequently, classroom learning is depreciated when many students choose not to attend lectures, which can affect student and teacher morale as well as institutional academic standards [8].

Several studies have reported that both students and faculty consider recorded lectures an effective alternative to attending live classes $[5,9]$. Students consider lecture capture a more convenient, efficient, and effective instructional method when compared to the time required to attend scheduled lectures [7]. Moreover, students use 
recorded lectures to clarify their understanding of complex concepts missed during live lectures [10] as well as providing an opportunity to listen to content at an individual's preferred pace $[10,11]$. Although studies have not reported the use of recorded lectures increased academic performance, some students believe otherwise [10]. Yet, students seem to want access to online recorded lectures and the opportunity to attend live lectures for increased flexibility in their learning [11-14]. Rae and O'Malley [14] reported that students having access to live and recorded lectures did not influence their decision to attend in-person lectures. While recorded lectures are viewed as a valuable method of instruction by faculty and administration, inperson lectures are still considered as an essential part of medical education [15].

Lecture attendance has been linked to faculty job satisfaction [5, 9]; thus, faculty are looking for ways to draw students back to the classroom [5,9]. It has been reported that some students attend lectures out of respect and professionalism; however, faculty do not believe this to be a pivotal reason for student attendance [5, 9]. A key reason for students' decision to attend live lectures appears to be related to the instructional methods used by lecturers [13, $16]$.

Several studies have reported that increased lecture attendance improved course examination performance and national board scores $[15,17,18]$; however, other studies suggest that academic performance is unaffected by lecture attendance $[7,12,19,20]$. Therefore, if lecture attendance and academic performance are equivocal, faculty derive job satisfaction with students lecture attendance, and live lectures continue as a common instructional method; teaching faculty and administrators must determine strategies that will encourage students' attendance of scheduled lectures.

A paucity of data exists as to which lecturer methods medical students rank as most useful to least useful in their decision to attend live lectures. Moreover, student comments from our previous work indicate that curriculum issues and policies play a significant role in students' decision to attend lectures [16]. To the authors' knowledge, there seems to be a gap in the literature regarding which non-instructor factors affect students' inclination to attend lectures (i.e., curricular issues/policies), as well as faculty perceptions to those factors and their effects on attendance. Therefore, the purposes of this study were to (1) determine a list of instructor methods from unimportant to very important by students along with curricular factors that influence students' decision to attend lectures and (2) better understand preclinical basic and clinical science faculty attitudes, perceptions, and behaviors relative to students' attendance of lectures and associated issues.

\section{Materials and Methods}

First-year (OMS I, $n=159$ ) and second-year (OMS II, $n=145)$ preclinical osteopathic medical students at the Arkansas College of Osteopathic Medicine (ARCOM) were invited to participate in the study, May and June 2020. This time frame spanned the conclusion of the spring semester and initial part of the students' summer break. The entire preclinical curriculum at ARCOM went from in-person delivery of content to an online curriculum (e.g., screencasts using Microsoft Teams) during the middle of the 2020 spring semester due to the COVID-19 pandemic. Student respondents completed a voluntary, anonymous 5- to 10-min online survey that consisted of four major sections, using SurveyMonkey ${ }^{\circledR}$. The first section of the student survey contained a two-part demographic question regarding year in school (OMS I or OMS II) and gender (male and female). The second and third segments of the survey asked students to rate 22 lecturer methods (e.g., ability to explain complex concepts in an understandable manner, communicates with appropriate volume/pronunciation/intonation, uses active learning strategies, and wears professional attire), and nine curricular issues (e.g., unscheduled time gaps between lectures, total number of lectures per day, time to upcoming graded assignments, and flexibility of recorded lectures for convenience) that affected students' decision to attend live lectures, using a semantic differential scale that ranged from 0 ("Not Important") to 5 ("Very Important"). The fourth component of the survey asked students five dichotomous questions ("Yes/No") related to live lectures and the ARCOM curriculum/policies. At the end of the survey, students were given an opportunity to provide optional, additional comments. The lecturer methods and curricular issues assessed in this survey were determined in large part from prior studies, including our own previous results.

Preclinical ARCOM faculty $(n=35)$ were also asked to take part in the study during May and June 2020. Faculty participants completed a three-section voluntary, anonymous survey on SurveyMonkey ${ }^{\circledR}$ that took 5 to $10 \mathrm{~min}$ to complete. In the first section of the survey, faculty were asked to identify their division (basic science or clinical science) and academic rank (Assistant Professor, Associate Professor, or Professor). In the second segment, faculty were asked to rate 17 factors about student attendance of lectures (e.g., attendance reflects a student's professionalism, job satisfaction is impacted by student attendance, and use of active learning strategies impact attendance), using a modified Likert scale in which 0 represented "Indifferent/Non-applicable" and 1 ("Strongly Disagree") to 5 ("Strongly Agree"). The third 
part of the survey consisted of a time scale, asking faculty the time required to either create new lectures (ranging from 1 to $17+$ hours) or update previously given lectures (ranging from 1 to 9 +hours). Like the student survey, faculty were also given an opportunity to offer comments at the end of the survey.

Student and faculty sample size was calculated based on a 90\% confidence level, population size for each group, and a 5-10\% margin of error. Demographic data were tested for statistically significant differences in distribution using chi-square test for independence. Statistical significance was set at $p<0.01$, using SigmaStat 4.0. Sematic differential data were treated as ordinal with median scores and frequencies reported for central tendency and variability, respectively. Dichotomous questions are reported via total percentages, whereas Likert scale items were analyzed as interval data with means and standard deviations reported for the location of the distribution and dispersion, respectively. These quantitative data are presented in tables of the "Results" section. The study was approved as exempt by the Arkansas Colleges of Health Education Institutional Review Board (FAS-2020-002).

\section{Results}

The sample size needed for students and faculty with a $90 \%$ confidence level, population size ( $n=304$ and $n=35)$, and $5-10 \%$ margin of error was 144 students and 24 faculty. One-hundred and forty-four students (47.4\%) completed the survey with 86 from the first-year class (45 female and 41 male) and 58 from the second-year class (33 female and 25 male). Although more OMS I and female students completed the survey, the difference was not statistically significant $(p=0.712)$.

Sematic differential scale data in Tables 1 and 2 show median scores (from high to low) and frequency of students' ratings for 22 lecturer methods and nine curricular issues that affected their decision to attend live lectures, respectively. Eight of the 22 lecturer methods had a median score of 5 (Very Important), whereas one lecturer method earned a median score of 1 (Not Important) suggesting a comprehensive panel of lecturer methods that influence students' decision to attend live lectures. For the nine curricular issues affecting students' attendance of lectures, three had a median score of 5 (Very Important), and the lowest curricular issue

Table 1 Student ratings of instructor methods for attending live lectures from 0 (Not Important) to 5 (Very Important)

\begin{tabular}{|c|c|c|c|c|c|c|c|}
\hline \multirow[b]{2}{*}{ Instructor methods } & \multicolumn{6}{|c|}{ Rating frequency } & \multirow[t]{2}{*}{ Median } \\
\hline & $\mathbf{0}$ & 1 & 2 & 3 & 4 & 5 & \\
\hline The lecturer can explain complex concepts in an understandable manner & 4 & 0 & 0 & 10 & 20 & 110 & 5 \\
\hline There is a clear, organized, and logical sequence to the lecture & 7 & 4 & 4 & 17 & 24 & 88 & 5 \\
\hline $\begin{array}{l}\text { The lecturer emphasizes important concepts during lecture and/or summarizes content at the conclusion of } \\
\text { lecture }\end{array}$ & 3 & 3 & 5 & 13 & 33 & 87 & 5 \\
\hline The lecturer begins and ends lecture on time & 9 & 4 & 1 & 16 & 32 & 82 & 5 \\
\hline The lecturer shows enthusiasm, which generates students' curiosity to learn the material & 4 & 3 & 4 & 22 & 30 & 81 & 5 \\
\hline $\begin{array}{l}\text { The lecturer communicates with appropriate volume, accurate pronunciation, and intonation (not } \\
\text { monotone) }\end{array}$ & 4 & 6 & 10 & 15 & 29 & 80 & 5 \\
\hline The lecturer provides clinical/practical applications of lecture material & 4 & 4 & 3 & 15 & 40 & 78 & 5 \\
\hline The lecturer conveys expert/authoritarian knowledge of subject & 4 & 4 & 8 & 16 & 38 & 74 & 5 \\
\hline Learning material contains minimal errors & 10 & 9 & 7 & 20 & 26 & 72 & 4.5 \\
\hline $\begin{array}{l}\text { The lecturer ties information together with either previously learned information or future course content in } \\
\text { the same course and/or other courses }\end{array}$ & 6 & 4 & 7 & 16 & 40 & 71 & 4 \\
\hline The learning material covers the subject matter adequately/appropriately to the level of the student & 7 & 6 & 6 & 21 & 35 & 69 & 4 \\
\hline The quantity of learning material (e.g., number of PPT slides) is appropriate for the allotted lecture time & 11 & 10 & 12 & 19 & 39 & 53 & 4 \\
\hline $\begin{array}{l}\text { Sufficient information (e.g., text) and appropriate images/figures/graphs are provided in the learning } \\
\text { material as opposed to one without the other }\end{array}$ & 7 & 10 & 15 & 24 & 29 & 59 & 4 \\
\hline The lecturer can gauge class understanding while lecturing & 6 & 5 & 15 & 30 & 31 & 57 & 4 \\
\hline The lecturer uses class time effectively and efficiently (e.g., avoids excessive anecdotes and humor) & 7 & 7 & 16 & 29 & 35 & 50 & 4 \\
\hline The learning material (e.g., PPT) is available for preview at least $24 \mathrm{~h}$ in advance of lecture & 26 & 16 & 9 & 20 & 33 & 40 & 4 \\
\hline Prelecture learning material given to students matches what is presented during lecture & 28 & 20 & 15 & 18 & 28 & 35 & 3 \\
\hline The lecturer uses active learning strategies during class (e.g., clickers, videos) & 19 & 17 & 17 & 30 & 30 & 31 & 3 \\
\hline The lecturer maintains eye contact with students during lecture & 23 & 16 & 23 & 33 & 22 & 27 & 3 \\
\hline The lecturer uses instructional aids effectively (e.g., wireless remote, stylus to scribe notes on slides) & 18 & 14 & 20 & 30 & 36 & 26 & 3 \\
\hline The lecturer wears professional attire & 74 & 9 & 15 & 23 & 11 & 12 & 0 \\
\hline
\end{tabular}


Table 2 Student ratings of curricular issues for attending live lectures from 0 (Not Important) to 5 (Very Important)

\begin{tabular}{|c|c|c|c|c|c|c|c|}
\hline \multirow[b]{2}{*}{ Curricular issues } & \multicolumn{6}{|c|}{ Rating frequency } & \multirow[t]{2}{*}{ Median } \\
\hline & $\mathbf{0}$ & 1 & 2 & 3 & 4 & 5 & \\
\hline Recorded lectures provide flexibility to learn material at a convenient time and/or pace & 1 & 3 & 7 & 4 & 22 & 107 & 5 \\
\hline Time to upcoming graded quizzes, course exam, and/or course assignment deadlines & 5 & 1 & 5 & 13 & 32 & 88 & 5 \\
\hline There are unscheduled time gaps between lectures & 11 & 4 & 6 & 10 & 27 & 86 & 5 \\
\hline Total number of lectures on a given day & 6 & 3 & 5 & 29 & 29 & 72 & 4.5 \\
\hline Personal schedule & 8 & 16 & 16 & 11 & 26 & 67 & 4 \\
\hline There is only 1 lecture scheduled after lunch & 20 & 8 & 10 & 18 & 33 & 55 & 4 \\
\hline Lecture time of day is between 7 a.m. and 9 a.m & 27 & 10 & 8 & 20 & 24 & 55 & 4 \\
\hline Lecture time of day is between 3 p.m. and 5 p.m & 31 & 7 & 10 & 19 & 25 & 52 & 4 \\
\hline Prior experience that the lecturer will likely not use the entire lecture period & 24 & 7 & 21 & 24 & 25 & 43 & 3 \\
\hline
\end{tabular}

received a median score of 3 . These results indicate that all nine curricular issues surveyed play a moderate to significant role in the students' decision to attend lectures.

Table 3 shows student responses to dichotomous questions (Yes/No) in relation to live lectures and ARCOM curriculum/policies. The results indicated that even with today's technology (e.g., recorded lectures), scheduled live lectures should continue $(60 \%)$. However, many students believe that ARCOM's mandatory lecture attendance $(88 \%)$ and assigned seating (78\%) policies should be eliminated.

Ninety-one students $(63 \%)$ provided written comments about these issues, with the most commented topic (52/91) focusing on flexibility and options for learning, which are incorporated in the "Discussion" section.

Twenty-one basic science $(n=11)$ and clinical science $(n=10)$ faculty $(n=35)$ completed the survey $(60.0 \%)$. Thirteen faculty respondents were Assistant Professors (61.90\%), five were Associate Professors (23.81\%), and three were Professors (14.29\%). Table 4 shows frequency and mean (standard deviation) for faculty ratings of 17 modified Likert scale questions, concerning lectures and students' attendance. The modified Likert scale used 0 to denote Indifferent/ Non-applicable, and 1 to 5 to represent Strongly Disagree and Strongly Agree, respectively. Results from both ends of the Likert scale were merged in Table 5. Four of the 17 faculty questions had a mean score of a 4.0 or greater, whereas six of the 17 faculty questions received a mean rating of less than three.

Teaching via lectures is a major job responsibility of ARCOM faculty, and medical schools frequently prescribe lecture preparation time within faculty adequacy models used for accreditation. Consequently, faculty were asked the time required to create new lectures and update previously given lectures, using two different time scales (Table 5).

\section{Discussion}

There were two major aims of the present study. First, we wanted to determine instructor methods during lectures, ranging from very important to unimportant from preclinical medical students' perspective. A second component of this goal was to ascertain non-lecturer curricular factors that influence students' decision to attend lectures. The second chief goal of the study was to better understand basic and clinical science faculty attitudes, perceptions, and behaviors toward students' attendance of lectures and related issues.

Results from our study show that students rated the ability to explain complex concepts in an understandable manner, having an organized and logical sequence to lecture, and either emphasizing or summarizing important lecture concepts as the most important instructor methods for attending
Table 3 Student responses to dichotomous questions related to live lectures and ARCOM curriculum policies

\begin{tabular}{lll}
\hline & Yes (\%) & No (\%) \\
\hline $\begin{array}{l}\text { With today's technology (e.g., recorded lectures), should scheduled in- } \\
\text { person (live) lectures be discontinued (if no, please explain in additional }\end{array}$ & $58(40.28)$ & $86(59.72)$ \\
$\quad$ comments)? & & \\
$\begin{array}{l}\text { Is/are there a lot of wasted/unused time within ARCOM courses (e.g., } \\
\text { lectures, lab, small group sessions ending well before the scheduled end } \\
\text { time)? }\end{array}$ & $117(81.25)$ & $27(18.75)$ \\
$\begin{array}{l}\text { Should the mandatory attendance policy at ARCOM be eliminated? } \\
\begin{array}{l}\text { Do you find the classroom setting distracting? } \\
\text { Should assigned seating the lecture halls be discontinued? }\end{array}\end{array}$ & $126(87.50)$ & $18(12.50)$ \\
\hline
\end{tabular}


Table 4 Faculty ratings to questions pertaining to lectures and students' attendance, ranging from 0 (Indifferent/Non-applicable) and 1 (Strongly Disagree) to 5 (Strongly Agree)

\begin{tabular}{|c|c|c|c|c|c|}
\hline & \multicolumn{4}{|c|}{$\begin{array}{l}\text { Rating } \\
\text { frequency }\end{array}$} & \multirow[b]{2}{*}{ Mean (S.D.) } \\
\hline & $\mathbf{0}$ & 1-2 & 3 & 4-5 & \\
\hline $\begin{array}{l}\text { In person scheduled lectures should continue to exist as a major mode of instruction in undergraduate medical } \\
\text { education }\end{array}$ & 0 & 3 & 3 & 15 & $4.19(1.17)$ \\
\hline $\begin{array}{l}\text { You believe students' decision to attend lecture is contingent on their attitudes about the topic (e.g., topic is } \\
\text { boring and/or do not like the subject)? }\end{array}$ & 0 & 3 & 1 & 17 & $4.14(1.38)$ \\
\hline $\begin{array}{l}\text { You encourage students who express difficulty with course material to attend live non-mandatory lectures } \\
\text { instead of watching the recorded lectures }\end{array}$ & 2 & 1 & 3 & 15 & $4.05(1.60)$ \\
\hline Your job satisfaction for teaching is impacted by student attendance of your lectures & 0 & 4 & 1 & 16 & $4.00(1.24)$ \\
\hline Attendance of live non-mandatory lectures reflects a student's professionalism & 0 & 5 & 5 & 11 & $3.62(1.36)$ \\
\hline The use of active learning strategies impact student attendance of non-mandatory lectures & 3 & 1 & 5 & 12 & $3.48(1.62)$ \\
\hline $\begin{array}{l}\text { Lecture halls with over } 100 \text { students can be intimidating for some lecturers, reducing their likelihood of engage } \\
\text { and interact with students }\end{array}$ & 0 & 5 & 6 & 10 & $3.38(1.26)$ \\
\hline There is a correlation between attendance of non-mandatory lectures and academic performance & 3 & 4 & 5 & 9 & $3.19(1.75)$ \\
\hline Student attendance policy should be determined by the course director & 1 & 9 & 2 & 9 & $3.19(1.64)$ \\
\hline $\begin{array}{l}\text { Lecture halls with over } 100 \text { students can be intimidating for some students, reducing their likelihood to attend } \\
\text { lectures and actively participate }\end{array}$ & 0 & 7 & 7 & 7 & $3.14(1.38)$ \\
\hline $\begin{array}{l}\text { Effectiveness as a teacher in conveying information and student understanding is correlated with the level of } \\
\text { student attendance }\end{array}$ & 2 & 7 & 5 & 7 & $3.05(1.66)$ \\
\hline Recorded lectures and/or screencasts is/are an effective alternative to attending scheduled live lectures & 0 & 10 & 6 & 5 & $2.81(1.06)$ \\
\hline Recorded lectures nurture independent study, fostering skills necessary for lifelong learning & 2 & 6 & 9 & 4 & $2.71(1.17)$ \\
\hline Student attendance for every lecture should be mandatory, regardless of either the course or a lab component & 4 & 10 & 3 & 4 & $2.48(1.67)$ \\
\hline $\begin{array}{l}\text { The COVID-19 pandemic, resulting in an online curriculum has changed my perception of mandatory lecture } \\
\text { attendance }\end{array}$ & 4 & 12 & 3 & 2 & $2.14(1.24)$ \\
\hline $\begin{array}{l}\text { You spend less time preparing for non-mandatory lectures that you know will likely result in low lecture } \\
\text { attendance }\end{array}$ & 4 & 13 & 3 & 1 & $2.10(1.24)$ \\
\hline You spend less time preparing for non-mandatory lectures compared to required lectures & 5 & 15 & 0 & 1 & $1.90(1.07)$ \\
\hline
\end{tabular}

live lectures (Table 1). Other lecturer methods that students considered important were starting and ending class on time, enthusiasm, understandability, practicality, and knowledgeable. Gupta and Saks [13] also reported that these lecturer characteristics were of the utmost importance to students.

Instructor methods with the lowest ratings from students in the present study were the use of active learning strategies and instructional aids, and professional attire. However, other studies reported active learning strategies encouraged students' critical thinking and engagement as well as positively influenced students' perception

Table 5 Time required by faculty to create new lectures and update previously given lectures

\begin{tabular}{lclc}
\hline New lectures & Respondents & Update lectures & Respondents \\
\hline $1-4 \mathrm{~h}$ & $0.00 \%$ & $1-2 \mathrm{~h}$ & $4.76 \%$ \\
$5-8 \mathrm{~h}$ & $4.76 \%$ & $3-4 \mathrm{~h}$ & $42.86 \%$ \\
$9-12 \mathrm{~h}$ & $33.33 \%$ & $5-6 \mathrm{~h}$ & $28.57 \%$ \\
$13-16 \mathrm{~h}$ & $23.81 \%$ & $7-8 \mathrm{~h}$ & $9.52 \%$ \\
$17 \mathrm{~h}$ or more & $38.10 \%$ & $9 \mathrm{~h}$ or more hours & $14.29 \%$ \\
\hline
\end{tabular}

of effective content delivery [20-22]. We have no data to explain why preclinical students in the present study rated active learning strategies and instructional aids as less important; however, it may be a future topic worthy of investigation. Speculations for the divergent outcome may be due to the individual strategies/aids being used and/or how the professors choose to implement them during their lectures; however, we lack data to support this supposition. Although students indicated that professional attire does not influence their decision to attend lectures in the present study (Table 1), Maxfield and colleagues [23] reported evidence of discrimination against facially unattractive and obese applicants in radiology resident selection. ARCOM stipulates that all faculty dress professionally for lectures (e.g., tie and/or sport coat for men). While instructor methods play a role in students' interest and willingness to attend lectures, our previous work [16] revealed that individual learning preferences, personal schedules, and curricular matters are likely involved in which curricular issues were examined in the present study.

The most important curricular issue affecting students' attendance of live lectures in our study was every lecture 
being recorded and available for students to access 24/7 shortly after each scheduled lecture (Table 2). Most student respondents rated the availability of recorded lectures as Very Important, and when given the opportunity to add voluntary comments at the end of the survey, more than one half of the noncompulsory comments (52 out of 91 ; $57 \%$ ) indicated that recorded lectures provided flexibility for learning the material at a convenient time, place, and pace. This finding is corroborated by other studies [11-14]. Faculty respondents in the study did not agree that recorded lectures/screencasts were an effective alternative to attending live lectures (76\%; Table 4$)$; however, no reasons were offered in the elective comments section of the faculty survey. A limitation of the present study was that students were not asked whether the cessation of lecture recordings would affect their decision to attend scheduled lectures.

Other curricular issues in our study that affected students' value of live lectures were time to an upcoming graded assignment or examination, unscheduled gaps between lectures, and total number of lectures per day (Table 2). Twelve optional student comments out of $91(13 \%)$ indicated that unscheduled timeslots between lectures played a role in their decision to attend scheduled lectures. Other comments in the optional feedback section of the students' survey indicated that their time was better spent preparing for upcoming exams instead of attending lecture(s), and/or they were in an optimal study mode and did not want to break it to attend lecture. Lecture time of day, whether early morning or late afternoon, as well as not lecturing the entire period were rated as less important to students (Table 2). Collectively, these findings suggest that an "engaging" lecturer may not be enough to drive students to the classroom and that curricular issues influence students' decision to attend lectures.

There are curricular policies at ARCOM that presumably exist to support students' academic standing, such as a mandatory lecture attendance policy for courses with a laboratory component (e.g., Osteopathic Practices and Principles and Fundamentals of the Anatomical Sciences) as well as an assigned seating policy for all lectures and courses. Most students in the present study believe the mandatory policies regarding attendance and assigned seating should be eliminated (Table 3 ) with optional student comments suggesting that students want more autonomy and self-responsibility. Faculty participants were not asked about the assigned seating policy; however, the majority of faculty disagreed that every lecture should have mandatory attendance (Table 4). Moreover, faculty were divided on whether students' attendance of scheduled lectures was correlated with academic performance in which this finding has been shown to be equivocal by others $[5,9,10]$.

Results from our study showed that many students and faculty agreed that scheduled live lectures should continue as a major mode of instruction during the preclinical phase of medical training (Tables 3 and 4). Voluntary student comments suggest that the reason for this finding may be attributable to individual student learning preferences. No comments were offered by faculty in the noncompulsory section of the faculty survey to explain why they think live lectures should continue. Other studies suggest that the value of lectures in medical education may be associated with efficient dissemination of contemporary content [3], educational opportunities offered in a large-group setting [4], and/or social interactions among students [5]. Yet, Gupta and Saks [13] and Schick and McWhorter [16] reported that students' perceived value of live lectures was in large part due to instructional methods/approaches of lecturers.

Most faculty in the present study believe that students' value of lectures was largely based on their attitudes about the subject matter rather than instructor methods (Table 4), whereas student participants considered lecturer methods and curricular issues determinants for attending lectures (Table 1). Most faculty in the present study either "Agree" or Strongly Agree that job satisfaction was impacted by students' attendance of lectures (Table 4), which is supported by Campbell and colleagues [5]. Because ARCOM faculty spend hours creating and updating lectures (Table 5), perhaps it is more palatable for faculty to believe students' attendance of lectures is driven by their interest in the content rather than the quality of instruction; however, this statement is speculative and not supported by the data from our study.

The time that ARCOM faculty spent preparing and/ or updating lectures in the present study was reported to not be affected by either low attendance or if the lecture was non-mandatory (Table 4). In the present study, faculty reported spending 9-12 h (33\%), 13-16 h (24\%), and more than $17 \mathrm{~h}(38 \%)$ preparing a new 50-min lecture (Table 5). Most faculty reported preparation time to update previously given lectures was on average between 5 and $12 \mathrm{~h}$. Both the Commission on Osteopathic College Accreditation (COCA) and the Liaison Committee on Medical Education (LCME) decree osteopathic and allopathic medical schools to develop a faculty adequacy model as a component of the accreditation process, which includes faculty time for lecture preparation and related teaching activities, service to the institution and one's profession, and research [24, 25]. Because neither COCA nor the LCME set a standard for the time required to develop instructional materials, medical schools must self-determine the time required by novice to experienced faculty to create and/or update lecture materials, which has practical implications that are beyond the scope of the present study. 


\section{Limitations}

This study was conducted using one cohort of first- and second-year students during a single academic year at one institution. First- and second-year student responses were combined to ensure an adequate sample size. A less-thandesired student response rate $(144 / 304 ; 47.4 \%)$ may have been related to the time of year data was solicited (i.e., end of spring semester and beginning of summer break).

\section{Conclusion}

While previous studies have shown that the "quality" of a teacher/lecturer is an important consideration for students' attendance of scheduled lectures, our study provides a list of instructor methods from most important to least important according to preclinical medical students. Moreover, our results show that curricular issues/policies (i.e., non-lecturer methods) affect students' decision to attend live lectures. The second major aim of our study showed that most faculty believe that students' attendance of lectures was based on their attitudes about the subject matter rather than instructor methods and that job satisfaction was impacted by students' attendance of lectures.

\section{Practice Points}

- Students may be more likely to attend lectures in which instructor methods that they deem important are utilized.

- Curricular practices and procedures play a role in students' decision to attend lectures.

- Medical students and faculty believe that live lectures should continue as an instructional method in the preclinical curriculum.

- Preclinical students want options in content delivery and oppose mandatory policies.

- Job satisfaction of faculty is influenced by students' attendance of live lectures.

\section{Glossary}

Lecture capture The process of recording classroom lectures as videos and making them available for students to review after the class, however, the term "lecture capture" is quite broad and can be used to describe a variety of solutions, software, and hardware.
Reference: https://www.techsmith.com/blog/lecture-capture/

Acknowledgements The authors thank first- and second-year medical students along with basic science and clinical science faculty at ARCOM for completing the student and faculty surveys, respectively.

Author Contribution The authors are responsible for the content of this article and are equal contributors.

Garrett Schick, M.A., currently a third-year medical student at Arkansas College of Osteopathic Medicine, will receive his D.O. degree in May of 2023. He received his Master of Arts of Biomedical Sciences from Midwestern University. David L. McWhorter, Ph.D., Professor and Chair of Anatomy at the Arkansas College of Osteopathic Medicine, Fundamentals of the Anatomical Sciences Course Director, and Director of the Arkansas Colleges of Health Sciences Anatomical Donation Program.

Data Availability Not applicable.

Code Availability Not applicable.

\section{Declarations}

Ethics Approval This research and survey was granted exception by the IRB at the Arkansas College of Osteopathic Medicine.

Consent to Participate Informed consent was obtained from all individual participants who participated in the study.

Consent for Publication The authors affirm that participants provided informed consent for publication of the results.

Conflict of Interest The authors declare no competing interests.

\section{References}

1. Alaagib NA, Musa OA, Saeed AM. Comparison of the effectiveness of lectures based on problems and traditional lectures in physiology teaching in Sudan. BMC Med Educ. 2019. https:// doi.org/10.1186/s12909-019-1799-0.

2. Zinski A, Blackwell KTC, Belue FM, Brooks WS. Is lecture dead? A preliminary study of medical students' evaluation of teaching methods in the preclinical curriculum. Int J Med Educ. 2017;8:326-33. https://doi.org/10.5116/ijme.59b9.5f40.

3. Simcock DC, Chua WH, Hekman M, Levin MT, Brown S. A survey of first-year biology student opinions regarding live lectures and recorded lectures as learning tools. Adv Physiol Educ. 2017;41:69-76.

4. Hoyt A, Mcnulty JA, Gruener G, et al. An audience response system may influence student performance on anatomy examination questions. Anat Sci Educ. 2010;3:295-9. https://doi.org/10.1002/ ase. 184 .

5. Campbell AM, Ikonne US, Whelihan KE, Lewis JH. Faculty perspectives on student attendance in undergraduate medical education. Adv Med Educ Pract. 2019;10:759-68.

6. Cardall S, Krupat E, Ulrich M. Live lecture versus videorecorded lecture: are students voting with their feet? Acad Med. 2008;83:1174-8.

7. Ikonne U, Campbell AM, Whelihan KE, Bay RC, Lewis JH. Exodus from the classroom: student perceptions, lecture capture technology, and the inception of on-demand preclinical medical 
education. The Journal of the American Osteopathic Association. 2018;118:813.

8. Rawlani SS, Rawlani SM, Lohe V, et al. Perception of dental faculty and student regarding class attendance and final performance. In: Journal of education and health promotion. 2018. https://www. ncbi.nlm.nih.gov/pmc/articles/PMC6332657/. Accessed 4 Jan 2021.

9. Zazulia AR, Goldhoff P. Faculty and medical student attitudes about preclinical classroom attendance. Teach Learn Med. 2014;26:327-34.

10. Hussain A, Tabrez E, Basu A, D'silva CSM. Medical students' perception of the usage of lecture recording software. Cureus. 2018.

11. Pettit R, Mccoy L, Kinney M. What millennial medical students say about flipped learning. Adv Med Educ Pract. 2017;8:487-97.

12. Azab E, Saksena Y, Alghanem T, Midle JB, Molgaard K, Albright S, Karimbux N. Relationship among dental students' class lecture attendance, use of online resources, and performance. J Dent Educ. 2016;80:452-8.

13. Gupta A, Saks NS. Exploring medical student decisions regarding attending live lectures and using recorded lectures. Med Teach. 2013;35:767-71.

14. Rae MG, O'Malley D. Do prerecorded lecture VODcasts affect lecture attendance of first-year pre-clinical Graduate Entry to Medicine students? Med Teach. 2016;39:250-4.

15. Demir EA, Tutuk O, Dogan H, Egeli D, Tumer C. Lecture attendance improves success in medical physiology. Adv Physiol Educ. 2017;41:599-603.

16. Schick GM, McWhorter DL. Factors influencing non-required lecture attendance for first- and second-year medical students. Wiley Online Library [Internet]. 2020. Available from: https://doi.org/ 10.1002/ca.23694.

17. Tang B, Coret A, Qureshi A, Barron H, Ayala AP, Law M. Online lectures in undergraduate medical education: scoping review. JMIR Medical Education. 2018;4.
18. Zureick AH, Burk-Rafel J, Purkiss JA, Hortsch M. The interrupted learner: how distractions during live and video lectures influence learning outcomes. Anat Sci Educ. 2017;11:366-76.

19. Paul S, Pusic M, Gillespie C. Medical student lecture attendance versus iTunes U. Med Educ. 2015;49:530-1.

20. Rezende AB, Oliveira AG, Vale TC, Teixeira LA, Lima AR, Lucchetti AL, Lucchetti G, Tibiriçá SH, Ezequiel OS. Comparison of team-based learning versus traditional lectures in neuroanatomy: medical student knowledge and satisfaction. Anatomical Sciences Education. 2019.

21. Cutler CW, Parise M, Seminario AL, Mendez MJC, Piskorowski W, Silva R. Should attendance be required in lecture classrooms in dental education? Two viewpoints. J Dent Educ. 2016;80:1474-8.

22. Dehghanzadeh S, Jafaraghaee F. Comparing the effects of traditional lecture and flipped classroom on nursing students' critical thinking disposition: a quasi-experimental study. Nurse Educ Today. 2018;71:151-6.

23. Maxfield CM, Thorpe MP, Desser TS, Heitkamp DE, Hull NC, Johnson KS, Koontz NA, Mlady GW, Welch TJ, Grimm LJ. Bias in radiology resident selection. Acad Med. 2019;94:1774-80.

24. American Osteopathic Association. New and developing accreditation standards. American Osteopathic Association [Internet]. 2020. Available from: https://osteopathic.org/wp-content/uploads/2018/ 02/com-new-and-developing-accreditation-standards.pdf.

25. LCME Standards, Publications, \& Notification Forms. LCME: functions and structure of a medical school. LCME Standards, Publications, \& Notification Forms [Internet]. 2020. Available from: https://lcme.org/publications/\#Standards.

Publisher's Note Springer Nature remains neutral with regard to jurisdictional claims in published maps and institutional affiliations. 